\title{
FORMAÇÃO DAS PRIMEIRAS INSTITUIÇÕES DE ENSINO SUPERIOR NO BRASIL ${ }^{1}$
}

\author{
FORMATION OF THE FIRST HIGHER EDUCATION INSTITUTIONS IN BRAZIL
}

\section{Gleison Peralta Peres}

Secretaria de Estado de Educação de Mato Grosso, Mato Grosso, MT, Brasil. E-mail: gleisonpp@ hotmail.com

DOI: https://doi.org/10.46550/amormundi.v2i1.54

Recebido em: 10.01.2021

Aceito em: 26.01.2021

\begin{abstract}
Resumo: Este texto é uma revisão de literatura que aborda a história do Ensino Superior brasileiro e seus desdobramentos durante o período colonial/imperial (1808-1889). O objetivo é descrever como ocorreu a ampliação do Ensino Superior no período. Apesar de sermos um dos últimos países da América Latina a ter instituiçóes de Ensino Superior, justifica-se nos dias atuais o nosso atraso educacional nesta modalidade de ensino.
\end{abstract}

Palavras-chave: Educação. Ensino Superior. História.

Abstract: This text is a literature review that addresses the history of Brazilian Higher Education and its developments during the coloniallimperial period (1808-1889). The objective is to describe how the expansion of Higher Education occurred in the period. Although we are one of the last countries in Latin America to have higher education institutions, our educational delay in this type of education is justified today.

Keywords: Education. University education. story.

\section{Introdução}

Educação não transforma o mundo. Educação muda as pessoas. Pessoas transformam o mundo (Paulo Freire).

A educaçáo deve permear a vivencia humana, proporcionando uma perspectiva Ide sociedade que venha a transformar as pessoas através da educação libertadora segundo Paulo Freire.

A história do ensino superior brasileiro, dos quais temos registro, são após 1808, quando são criadas as primeiras escolas superiores, que buscavam a formação para as profissóes liberais tradicionais, como direito, medicina e para as engenharias.

Por muitos anos essas perspectivas do ensino superior permaneceram, modificando

1 Este texto é um recorte do primeiro capítulo da pesquisa de Mestrado em História da Pontifícia Universidade Católica de Goiás, defendida em 20 de fevereiro de 2019, pelo autor do texto, porém foi revisado e atualizado para esta publicação. 
somente em meados do século XIX, onde foram introduzidas uma formação mais tecnológica, porém neste caso, desde o início vemos uma descontinuidade em relação ao papel do Estado.

Acreditamos que este texto possa, contribuir para a formação de pesquisadores da área do ensino superior brasileiro no campo da história da educação.

\section{Ensino Superior: breve histórico}

A educação brasileira, e a de criação das instituiçôes de nível superior, são marcos fundamentais para compreender o processo de criação e implantação das instituiçôes de nível superior brasileiras foi tardio, passou por momentos de desestímulos, na maioria das vezes propositais, no intuito de manter o Brasil como colônia portuguesa, vindo a romper essas amarras somente em 1822, com o processo de independência. Vale ressaltar que a importância histórica da trajetória educacional brasileira como a mencionada por Cunha (2000, p. 152) se deu:

Diferentemente da Espanha, que instalou universidade em suas colônias americanas já no século XVI, Portugal não só desincentivou como também proibiu que tais instituiçôes fossem criadas no Brasil. No seu lugar, a metrópole concedia bolsas para que certos números de filhos de colonos fossem estudar em Coimbra, assim como permitia que estabelecimentos escolares jesuítas oferecessem cursos superiores de Filosofia e Teologia. O primeiro estabelecimento de Ensino Superior no Brasil foi fundado pelos jesuítas na Bahia, sede do Governo Federal, em 1550. Os jesuítas criaram, ao todo, 17 colégios no Brasil, destinados a estudantes internos e externos, sem a finalidade exclusiva de formaçáo de sacerdotes. Os alunos eram filhos de funcionários públicos, de senhores de engenho, de criadores de gado, de artesãos e, no século XVIII, também de mineradores. Nesses colégios era oferecido o ensino das primeiras letras e o ensino secundário. Em alguns, acresciase o Ensino Superior de Artes e Teologia. O curso de Artes, também chamado de Ciências Naturais ou Filosofia, tinha duração de três anos. Compreendia o ensino de Lógica, de Física, de Matemática, de Ética e de Metafísica. O curso de Teologia, de quatro anos, conferia o grau de doutor. Em 1553, começaram a funcionar os cursos de Artes e de Teologia. No século XVIII, o Colégio da Bahia desenvolveu seus estudos de Matemática a ponto de criar uma faculdade especifica para seu ensino. Cursos superiores foram também oferecidos no Rio de Janeiro, em São Paulo, em Pernambuco, no Maranhão e no Pará.

No período Imperial, segundo Ghiraldelli Jr. (2015, p. 33), o ensino era estruturado em três níveis: primário, secundário e superior. O primário era a "escola de ler e escrever" e o secundário "esquema das aulas régias", como estrutura inicial, o Ensino Superior tinha pouca expressividade, pois servia para manter os privilégios da elite brasileira, com poucas faculdades no território nacional.

Em relação à criação das instituiçôes de Ensino Superior no Brasil, veio tardiamente, principalmente enquanto éramos Colônia de Portugal (até 1822), cujo comércio era basicamente da monocultura extrativista. As riquezas brasileiras eram enviadas à metrópole, e neste cenário, não havia preocupação em criar instituiçôes de Ensino Superior no Brasil que proporcionassem oportunidades de acesso ao ensino e à pesquisa à populaçáo que, na maioria era pobre, pois instruída, poderia ameaçar os interesses da elite portuguesa. Algumas mudanças ocorreram com a vinda da Família Real para o Brasil.

Cale ressaltar que nosso país, foi um dos últimos países da América Latina a criar 
instituiçôes de nível superior, como afirma Teixeira (1976, p. 244): "O Brasil constitui uma exceção na América Latina: enquanto a Espanha espalhou universidades pelas suas colônias eram 27 ao tempo da independência - Portugal, fora dos colégios reais dos jesuítas, nos deixou limitados as Universidades da Metrópole: Coimbra e Évora”.

Percebemos que além da pouca expressividade do ensino e da pesquisa no nível superior, a memória dos processos de implantação das instituições mesmo tendo ocorrido tardiamente, nos possibilita a compreensão da escolarização nos dias atuais. Diante das informaçóes que temos disponíveis, devemos, portanto, refletir criticamente, buscando dialogar com os movimentos no nível internacional, como aponta Cunha (2000), pois para compreendermos o receio que houve por parte do colonizador, de que os estudos universitários viessem a contribuir com a disseminação do Iluminismo ${ }^{2}$ no Brasil, e influenciassem o posicionamento crítico em território nacional.

Em relação às primeiras escolas de nível superior ${ }^{3}$, Martins apud Cunha (2002, p. 1) realiza o histórico inicial do Ensino Superior brasileiro, dizendo que este somente foi instalado após a vinda da Família Real no Brasil em 1808, quando esta sofrera ameaças da invasão napoleônica em $1807^{4}$ a Portugal e, então tivera que fugir às pressas para o Brasil.

As primeiras escolas de Ensino Superior foram fundadas no Brasil em 1808 com a chegada da família real portuguesa ao país. Neste ano, foram criadas as escolas de Cirurgia e Anatomia em Salvador (hoje Faculdade de Medicina da Universidade Federal da Bahia), a de Anatomia e Cirurgia, no Rio de Janeiro (atual Faculdade de Medicina da UFRJ) e a Academia da Guarda Marinha, também no Rio. Dois anos após, foi fundada a Academia Real Militar (atual Escola Nacional de Engenharia da UFRJ). Seguiram-se o curso de Agricultura em 1814 e a Real Academia de Pintura e Escultura.

Em relação aos dados descritos por Martins (2002), percebemos que a implantação das escolas de nível superior no litoral, foi para atender aos anseios da elite portuguesa que aqui havia se instalado, evitando assim, seu deslocamento para a Europa para realizar os estudos de nível superior.

Percebemos, ainda que Cunha (1988, p. 43) relaciona a evidência de valorizar o litoral, principalmente, no Rio de Janeiro e Bahia, como forma de qualificar a elite que moravam nestes locais 5 .

A obra resultante da mudança da sede do reino praticamente se limita ao Município da Corte e à Bahia, onde são criados os primeiros cursos superiores, com o objetivo de servir aos interesses imediatos dos renóis recém-transferidos. O legado deste momento histórico, todavia, ultrapassa tais objetivos, avançando noutras direções.

2 O Iluminismo foi um movimento global, ou seja, filosófico, político, social, econômico e cultural, que defendia o uso da razão como o melhor caminho para se alcançar a liberdade, a autonomia e a emancipação. O movimento iluminista utilizou da razáo no combate à fé na Igreja e a ideia de liberdade para combater o poder centralizado da monarquia. Com essa essência, transformou a concepção de homem e de mundo (Nota do autor, 2020)

3 O termo escolas de nível superior ou faculdades, se refere ao período imperial, já que o termo Universidades só aparece após a criação da Universidade Federal do Rio de Janeiro (UFRJ) também conhecida por Universidade do Brasil em 7 de setembro de 1920 através do decreto no 14.343 do então presidente Epitácio Pessoa. (Nota do autor, 2020)

4 Este fato ocorreu no final de 1807, devido Portugal não acatar o Bloqueio Continental imposto por França e Inglaterra aliadas na época, mantendo a exclusividade comercial dos produtos portugueses. (Nota do autor, 2020)

5 Fica evidente que os portugueses só criaram as escolas de nível superior para atender uma pequena parcela da população brasileira, justificando assim nosso atraso em relação ao Ensino Superior brasileiro, pois tinham o intuito de explorar o território brasileiro. (Nota do autor, 2020) 
Vieira e Farias (2007, p. 16) afirmam que as faculdades criadas eram nas áreas: engenharia, direito e saúde, principalmente, para dar "algumas condiçóes de sobrevivência aos portugueses que chegavam e, ao mesmo tempo, assegurar uma educação para a convivência social", bem como manter o prestígio social perante a sociedade ${ }^{6}$ com status de profissional diplomado e sendo as áreas que demandavam de mais profissionais habilitados.

Em relação aos cursos de nível superior criados de 1808 à 1889, Coelho e Vasconcelos (2009), afirmam que haviam 19 cursos de Educação Superior no Brasil e os cursos eram voltados à formação de profissionais liberais, com eventual prestígio social naquela época.

Percebemos que, no período imperial, nosso país era predominantemente agrário e a população era composta pela maioria de escravos, indígenas e mestiços, e que a educação não era prioridade, como afirma Cury (2000, p. 13).

[...] num país pouco povoado, agrícola, esparso e escravocrata, a educação escolar não era prioridade e nem objeto de uma expansão sistemática. [...] A educação escolar era o apanágio de destinatários saídos das elites que poderiam ocupar funçóes na burocracia imperial ou no exercício de funçóes ligadas à política e ao trabalho intelectual.

Inúmeros eram os problemas no projeto educacional brasileiro, que diante dos poucos cursos de nível superior, tinham como principal objetivo na transmissão da cultura elitista e alienante como afirma Teixeira (1998, p. 93-94).

[...] tínhamos duas alienações no Ensino Superior. A primeira grande alienação é que o ensino, voltado para o passado, nos levava ao desdém pelo presente. A segunda alienação é que toda a cultura transmitida era cultura europeia. E nisso tudo o Brasil era esquecido.

Em relação aos direitos constitucionais do período, cabe mencionar que em 1824, foi outorgada nossa primeira Constituição Imperial trazendo a garantia da instrução primária, como direito individual (artigo 179), porém, mantinha o catolicismo romano como religião oficial, que já vinha atuando desde o período colonial através das missôes jesuíticas, principalmente, na educação, como afirmam Haddad e Pierro (2007, p. 86):

[...] a primeira Constituição brasileira, de 1824, firmou, sob forte influência europeia, a garantia de uma "instrução primária e gratuita a todos os cidadãos", portanto, também para os adultos. Pouco ou quase nada foi realizado neste sentido durante todo o período imperial, mas essa inspiração iluminista tornouse semente e enraizou-se definitivamente na cultura jurídica, manifestando-se nas Constituiçóes brasileiras posteriores. O direito que nasceu com a norma constitucional de 1824, estendendo a garantia de uma escolarização básica para todos, não passou da intençấo legal.

Apesar da garantia constitucional em 1824, não houve avanços, principalmente na Educação Superior, já que estava voltada para o ensino primário; porém, em 1834 com a criação do ato adicional, várias modificaçóes aconteceram. Romanelli (2013, p. 40), aponta algumas mudanças significativas dentre elas, a "descentralização ocorrida com o Ato Adicional de 1834 [...] que delegou às províncias o direito de regulamentar e promover a educaçáo primária e secundária." Percebemos, que não havia interesse na expansão do ensino brasileiro em qualquer nível de ensino.

6 Neste caso abordamos sociedade no sentido de prestígio entre as pessoas, com grau de estudos elevados, ocupando cargos importantes (públicos ou privados). (Nota do autor, 2020) 
Cabe ressaltar que a partir de 1870, o Brasil vive um período de inúmeras transformaçóes em vários setores, em relação ao período. Neto (2015, p. 102), menciona algumas mudanças, neste processo de modernização do país:

O crescimento das cidades; o crescimento do número de imigrantes que chegavam ao país; a expansão da malha ferroviária; o crescimento do sistema bancário e de crédito; a modernização da agricultura; a substituição do trabalho escravo pelo trabalho livre; a expansão da cafeicultura; a diversificação da economia; a expansão do mercado interno; a introdução do capital estrangeiro na economia do país; a introdução do capitalismo industrial.

Diante das mudanças na sociedade brasileira, aliadas às transformaçóes políticas, em 15 de novembro de 1889 , foram materializadas no decreto $n^{\circ} 1$ que proclamou a República Federativa do Brasil, onde o passaríamos à condição plena de mudanças institucionais de representatividade pelos diversos grupos envolvidos no processo de mudanças e de acesso educacional em território nacional.

\section{Consideraçóes finais}

Todo o processo educacional brasileiro, foi sendo implantado de forma muito lenta, e o Ensino Superior, só aconteceu devido a vinda da Família Real para o Brasil, que foi criado para atender a elite.

Diante dos apontamentos, acreditamos que o Ensino Superior brasileiro, ter sido iniciado de forma tardia, os impactos por sua implantação são refletidos até os dias atuais. Cabe a nós brasileiros, defendermos a instituiçóes públicas no intuito de ampliar e garantir o acesso a toda população.

\section{Referências}

COELHO, Sintia Said. VASCONCELOS, Maria Celi Chaves. A criação das instituiçóes de ensino superior no Brasil: o desafio tardio na América latina. Anais do IX Colóquio Internacional sobre Gestão Universitária da América do Sul. Florianópolis. 2009.

Disponível em <https://repositorio.ufsc.br/bitstream/handle/123456789/37012/A\%20 cria $\%$ C3\%A7\%C3\%A3o\%20das\%20institui\%C3\%A7\%C3\%B5es\%20de\%20ensino $\% 20$ superior\%20no\%20Brasil\%20O\%20desafio\%20tardio\%20na\%20Am\%C3\%A9rica $\% 20$ Latina.pdf?sequence=1> Acesso em 02 de maio de 2018.

CUNHA, Luiz Antônio. 500 anos de Educaçáo no Brasil. Belo Horizonte: Autêntica, 2000.

CUNHA, Luiz Antônio. A universidade reformanda: O golpe de 1964 e a modernização do ensino superior. Rio de Janeiro: Francisco Alves, 1988.

CURY, Carlos Roberto Jamil. Diretrizes Curriculares Nacionais para a Educaçáo de Jovens e Adultos-Parecer CEB n. 11/2000. Resolução CNE/CEB 1/2000, publicada no Diário Oficial da União de 19/7/2000, Seção 1, p. 18.

HADDAD, Sérgio; PIERRO, Maria Clara Di. Escolarizaçáo de Jovens e Adultos: educaçáo como exercício de diversidade. Brasília: UNESCO; MEC; ANPEd, v. 7, p. 476 (Coleção Educação para Todos). 2007. 
MARTINS, Antônio Carlos Pereira. Ensino superior no Brasil: da descoberta aos dias atuais. Acta Cir. Bras. vol. 17, suppl.3, São Paulo, 2002. Disponível em <http://www.scielo. br/scielo.php?script=sci_arttext\&pid=S0102-86502002000900001 > Acesso em 14 de abril de 2018.

ROMANELLI, Otaíza de Oliveira. História da Educaçáo no Brasil. 39a ed. Petrópolis, RJ. Vozes. 2013.

TEIXEIRA, Anísio Spínola. Educação no Brasil. 2a edição. São Paulo: Ed. Nacional, Brasília, INL, 1976.

TEIXEIRA, Anísio Spínola. Educaçáo e Universidade. Rio de Janeiro: Editora da UFRJ, 1998.

NETO, Alexandre Shigunov. História da educaçáo brasileira: do período colonial ao predomínio das políticas públicas educacionais neoliberais. São Paulo. Salta. 2015.

VIEIRA, Sofia Lerche. FARIAS, Isabel Maria Sabino de. Política educacional no Brasil: introduçáo histórica. Rio de Janeiro: Liber Livro, 2007. 